\title{
中國科嚳院學習蘇聯先進科學 經驗交流座談會總結
}

\author{
武衡 \\ （中國科學院秘畫處副秘書長）
}

解放以來, 中國科眾院各研究所都先後開始 了學㚙蘇聯, 學柏俄文。通過 1952 年的思想改造 㚙運動, 學晳蘇聯的熱情更加高浱了。1953 年 初, 全院普遍開展了俄文專業等籍閱讀速成學㚙。 同年 2 月，毛主席號召我們“不僅要學替馬克思、 恩格斯、列密、斯大林的理論, 而且要學晳鮛聯 先進的科擧技街。我們要在全國籍圍內损起學晳 蘇聯的高潮，來建設我們的國家。”在毛主席號召 的鼓舞下，一年多來，我們在學習俄文、學晳蘇 姺淮科祭技街方面都有了廣泛的開展。訪蘇代 表国誾國後的傳達報告, 更加提高了我們學習蘇 聯的熱情與信心。

到目前第止, 中國科學院全體研究人員中, 已有 $93.2 \%$ 學習了俄文, 有 $73.5 \%$ 已能閲讀蘇聯

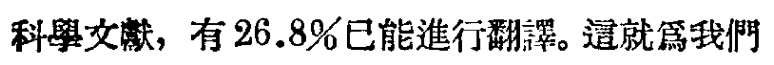
進一步祭習蘇聯先淮科學刢造了有利的條件。

在俄文學翟的基礎上, 各研究單位一共翻澤 了 1,500 萬字的蘇聯科交交俭。這對於科學研究

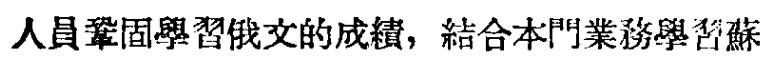
聯先淮科學, 以及向我國科學界傳播蘇㽧先進科 舆經驗等, 都起了一定的作用。

近一年多來, 各研究所已比較普遍地開展了 閵於蘇聯先進科學理論和先進科學成就的學習, 並開始將學習的收檴運用到賽際工作中去。例如， 生物科置方面各研究所, 都先後分别開展了關於 米丘林鼠說、巴甫洛夫學說和勒柏辛斯卡姪學說 的系統學習。有不少科學家並已開始在自己的研 宪工作中, 運用了迶些先進的科學理論, 開始批 判了自己過去䧄不正確觀點。文如地球物理研究 所以及技微科各研究所, 在許多問題的研究中,
都是由於參考和運用蘇聯科學研究的成果, 從而 得以克服工作中的困難，取得了一定的成績。有 的研究單位, 如數學研究所斯諭組和力祭研究空

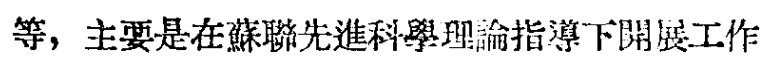
的。此外，有關物理鼠、化學及砋會科學的各研

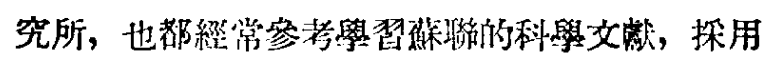

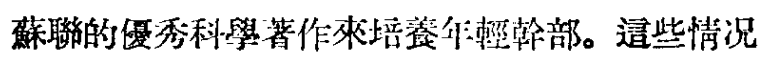
說明了蘇聯先進科學的影響已日益深入到我們科 學工作售践的各個方面中去。

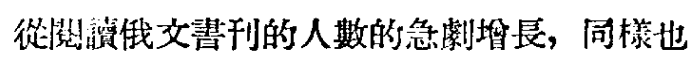

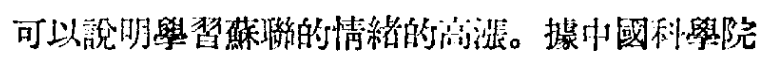
圖洁舘上海分舘緿計，今年 1 月到 4 月，俄文步

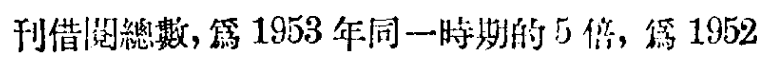
年同一特期的 50 倍。少北各研究所俄文丵刊出 借閱讀的一般都佔出借圆悲總數的 60\%上下。許

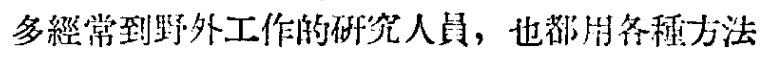

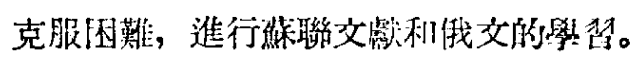

特别仵得提出的, 有若一湖究所得到了在我

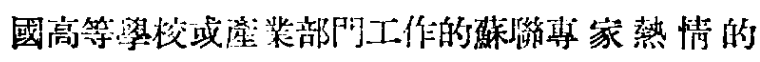
指導與大力的幫助。例如石泪的呼究和煤兴的研

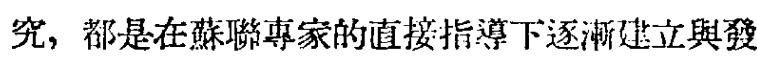
展起來的, 並且獾得了不少的成結。

我們狺次座談會的中心队容是交流學陆蒛聯 先進科學的經驗。但是會議所涉的籍阔是十分展

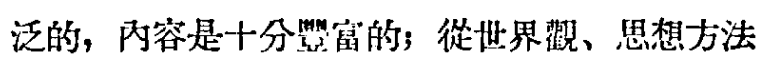
到具體的實驗技術，從各門科翼的發屡方向到某 些工作的具體婹求，從研究工作的組繶領導到科 學幹部的培養, 從學習俄文到文䖪資料的搜集等, 蘑不多都談到了。通過這愫一次廣泛的經驗交流, 無疑地將淮一步促使我们更好地學習俄文及祭習 
莎先進科學，推動我們學術討論和批評與自我 批評的展開, 以蘇聯科學的先進榜樣來發展新中 國的科學事業。

這次會議的收蕜是多方面的，而其中最重要 的則是思想認識上的收穫。

大芜在思想認識上的第一個重要收檴是開始 從自己筫際的研究工作中認識到誩證唯物主義世 界颧對科學工作的巨大指導作用，從而使自己更 明確地樹立了唯物主義的世界觀。

我們的生物學工作者學㚙了米丘林、李森科 的舁說:, 認識了“生物體與其生存環境條件統一”。 對於程的形成、遺傳及其變異、費育的階段性等有 了正確地理解。批判了崔的傅統中形而上學的思 想方法和唯心主義的觀點，因而就有可能來正確 地認裁生物, 研究生物, 定向地改造生物决篇人類 服枒。會議上詐多代表都進行深到的自我批評，亚 检查了過去的工作。如陳槕先生检查了過去所作

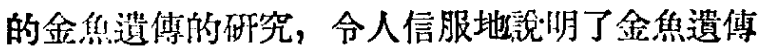
及環境的關係，指出孟德爾一摩爾根主義的錯哭。

我們的土壤學工作者學替了威麻斯學說後, 認識到土埕是一種特殊的自然物體, 是在植物與 微生物不可缺少地參加下, 在人類勞動影響下形

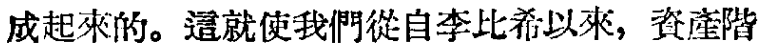
級土壤學者形而上學的觀點和方法中解放出來， 正確地對待土壤肥沃性的問題，從而給土壤科學

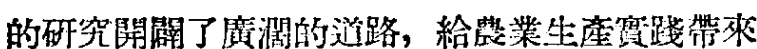
巨大的利谷。

我們的心理學工作者學習了巴甫洛夫的學 詮，對於人類認識與思維的物質基礎、人類高級

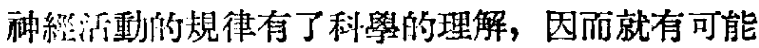
把心理學儌研究建立在利學的基礎上，從而批判 了资產階級的行篇主義和完形學說等錯誤觀點。 在會菨上，心理㸴究室的同志會介紹了他們思想 轉變過程及研究工作的收檴。

我們的物理學工作者學習了蘇聯科學家對量 子力學中唯心論的批判，改戀了對徽觀址界的看 法，澄清了資產階級的“物質的運動取决於觀測 者, 取决於人”，“微觀世界不可認識”的唯心㖉 䜽，掃除了自己在近代物理學的理論研究中的思 想障碍。

其他的科哥工作者同槏地也由於學晳了蘇聯 先淮科學，在思想認識上及思想方法上都有了很
大的進步。他們深深地體會到蘇聯科揫之所以是

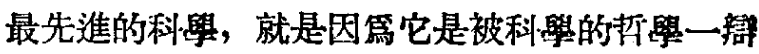
證唯物主義所武装起來的, 就是因第它以誰證唯 物主義的思想武器向备門科貢中各出各樣的唯心 諭的阷曲作不調和的网爭中成長起来的。而我們 學習了蘇聯的先淮科學，也就使我們有可能通過 本門科學來掌握徬證唯物主義一一馬克思列蜜主 義的世界觀與方法諭，有可能批刵各種各樣的資 産階級反動的落後的學說，批判自己過去所受造 些學說的影響，批判自己過去工作中的錯韶。道 些批判不僅提高了自己, 同時也呚育了其他同志, 敉育了青年。邆喠批評和自我批評的精耐古溢在

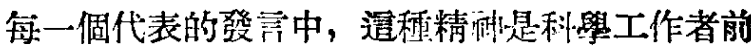
進的動力，是科貾發展的動力。

會議發言中的無数事例都指明了科學工作者 學習馬克思列察主義及飞主席著作的重要意義。 科學研究工作是思想工作，是創造性的勞動。不 管從事這種思想工作的人的主觀願望如何，他不 受這一種世界觀的支配，就受另一種世界觀的支 配，詐多代表發言中指出當他們未接受辩證唯物 主義的世界觀以前，思想方法上徍往是形而上學 的，把自然界及㣂會現象看作是彼此孤立的、静

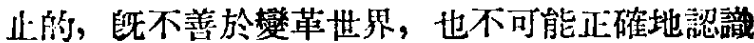
世界，從而導向“不可知諭”、“紹對觀念”等唯心 主義的迷宾中去，因而大家進一步認識到哲學思 想是必然影響科學工作的，科學工作者應當加婜

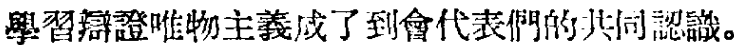

在思想認識上第二做收獲是對理論聯系賴際 的方䣄，有了進一步的理解。從而明確了本門科 學的研究方闬。

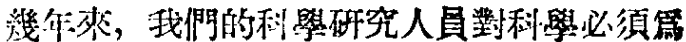
國家建設服務，理諭必須與䨘際結合有了認䜾。 但是對於自己從事的那一門科學，究竟應如何聯 系實際，如何篇國家建設服務，還不很明確，或 有很多問題。某些研究部門的研究人員, 認第他 們的工作無法結合害際，無從䉆國家建設服務， 找不到研究工作方向，因而浐得苦悶。例如植物 形態學、植物分類學、頲傅學、古植物學、細胞 學、心理學等就有這樣情形。通過了燢替蘇聯先 進科學，這種思想逐漸被澄清了。

植物形態學工作者認識了植物形態學吅以通 過十分廣泛的領域來第工農業生産服務，因而大 
大提高了工作的熱情和信心。如花粉學的研究在

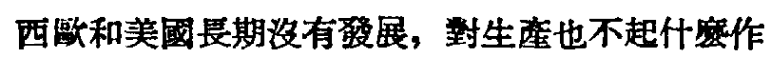
用。在蘇聯, 花粉學與地質工作相結合, 有了巨 大的發展。我們的科學工作者從造裹也體會到科 臬只有結合實際才能得到迅速的弡展。細胞學工

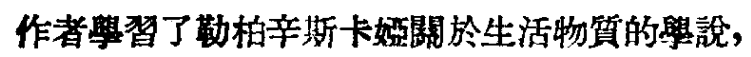
因而明確了細胞學研究的方向。

在思想認識上第三個收檴是工作作風與工作 態度有了改淮。通過學㚙独聯先進科學以及得到 落聯鱼家的㨁接指導，我椚的科學工作者對蘇聯 科學家的愛國主義與國際主義精神、筫事求是的 科學態度、社會主義的勞動態度、批評與自我批 的的精神、科學工作人員與生產革新者的創造性 合作等等, 也都有所體會。例如, 陳煥鏞先生在會 議上說他過去會經舃過一本“中國經流樹木祭”, 談到中國的特座杜仲時, 認篇杜仲是没有筫用㑑 值的。但經蘇聯科學家的研究, 知道了杜们是治 高血㻺症的特效鞄，他們並改良了杫他的性狀。 又如石油研究所的同志所介紹的, 㸚年來, 先後有 穖位綜聯專家在其本身工作十分繁重的條件下， 到我們的研究所裹指導工作，不嗼在學術上對我 們有極大的墭助, 在工作方法上、工作態度上都給 我們以極大啓發和幫助。他們都是循循善誘、不 解疲勞地給我們䎟助, 急切地齐望中國科學事業 迅速地成長壮大。㯰種偉大的國際主莩精种和社 合主義答動態度, 給我們以巨大的鼓舞力量。其他 研究單位的闰志，只要有機會和蘇聯專家接触， 也都有同樣的感睍。

其次是在研究工作方面的收㩲。學㚙蘇聯使 我們的思想認識提高了, 研究工作的方洞明確了, 工作皘極性提高了, 隨之丽來的就是具體研究工 作的收磼。造個收穫目前邈只是開始, 今後必將 不嵫地撗大。例如, 生物學工作者運用了米丘林

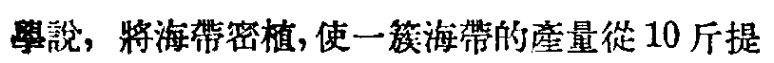
高到 160 斤。菌種的相攰體等問题的研究上，也 有了一定的成績。心理學工作者學晳了巴甫洛 大照說，開始建立了焂件反射試驗室，第進一步 開展研究，創造了佟件。氣象學工作者學㕷了蘇 聯先進的氣像理論和方法，創造性地運用到中國 中期天氣預報的研究中去, 獾得了良好的成樍。 海洋量工作者運用了蘇聯先進的海水分析方法改 淮了海水分析工作。地質䝿工作者罣替了蘇聯先

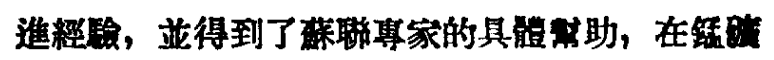
的資源勘查上取得了巨大成果。技術科學工作者

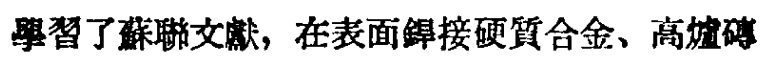

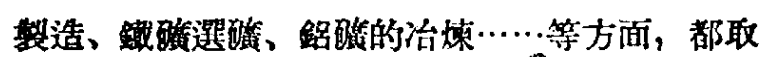
得了不少成績, 支援了國家建設。化學工作者探

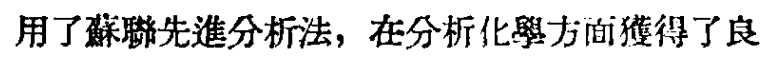
好成樍，縮短了工作時間; 對有機矽的原料問題, 也得到了適當的解决。石油科學工作者在石油分

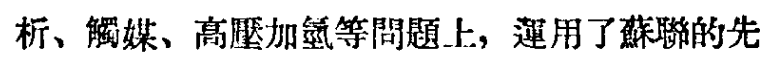
淮經驗, 取得了一定的成績。蝶岑工作者根據了 蘇聯標準, 結合了我國當前賽際情况訂出了我國 煤炭區域標隻, 篇工業用煤規範化提供了初步的 基礎。其它如電火花加工、電子管設計、鋼玉貿 瓷刀的試製、建築材料的研究……等, 也都依㭉 學替蘇聯取得了不少成樍。這裹所舉的一些例 子, 只是在譄次會議上.所提到的一部分, 智然逼 不足以代表各研究單位賽際工作中所取得的許多 成樍的。此外，在制訂研究計劃、唔飬利學幹部和 科學研究機構的組織領導等方面，各研究所也都 或多或少地吸取了蘇聯先進經聽，改進了工作。

由於以上的收椱，大家對蘇聯科學的先進性 及優越性都有進一步的體會, 體會到蘇聯科學篇 什宛能在較短的時間內在許多方面超過了凘本主 義國家，佔揞了世界第一位。蘇聯科學是先 進 的，優越的，首先由於它是建立在徬證唯物主義 世界觀的基礎上的，是密切地和社會主義與击应 主義建設相聯系的。其次，還由於蘇聯利舆釉承 了人類歴史上一切的優秀的科學頲産, 棕合了世 界各國的科學研究成果，加以發拐光大。蔇聯科 學家是洺有階級偏見的，這與復朾的、沟落的資

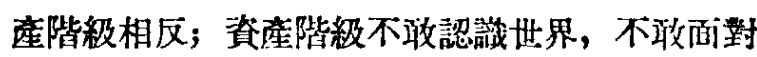

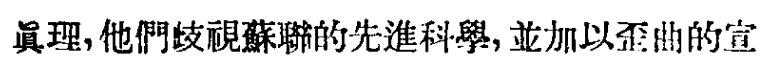

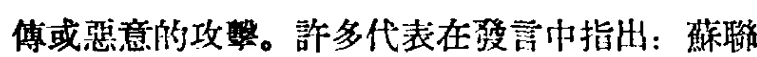

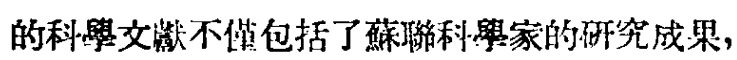

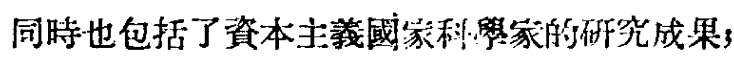
相反的，資本主義國家的文鹳不是测口不談蘇聯 的科學成就，就是㴓意地加以露曲。

郭泝若院長曾經指出: “随着革命事業在 各 個方面的勝利，……我國的科學事業阔樣也起了 根本的變化”,道個根本變化不僅表現篇科學研究 機構及科燢䂙究工作轉變第人民严業㯰個根本性

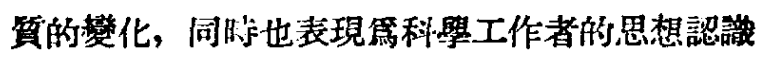


及學術思想上的變化，濖個變化的影響是多方面 的, 它將日益顯示其不可估量的作用。

在等習蘇聯先進科學方面，我們已經取得了 不少成績, 但譄些成綪還只是初步的。在擧替中, 還存在着許多缺點。其中最主要的有下列三方面:

第一，院和一部分研究所的領導只有一般的 號召, 缺乏具體的領蒥, 没有及時地總結和交流 經驗。

學習蘇聯先進科學，一般地說, 領導上是重 視的; 但究竟應賞如何學, 從何學起, 大家都没 有經騟，也拿不出一套辦法隶。因此及時總結經 驗, 交流推廣䌈驗, 就成篇十分必要的了。但在 過去, 領導上没有很好地運用“從翌衆中來, 到萃 采中去”的工作方法, 有作置、有检枯地來推動學 替。加以不了解實際情况, 使學得好的得不到表 拐, 繁得不好的也没有批評; 好的經驗不能及時 推廣，錯誤和缺點也不能及時䊼正。

院對各所的高級研究人員 (特别是所長、副 所畏）習蘇聯先淮科學和學架俄文的時間沒有 設法加以保證。因而有部分的高級人員忙於行政

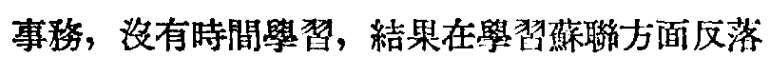
後於被領導的青年幹部。年輕幹部利、學水本低, 理解程度美, 如無高級人員的指導, 往往花了很 多時間，收效還是不大。

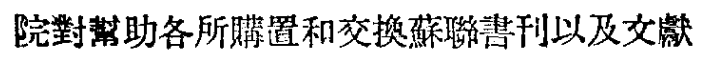

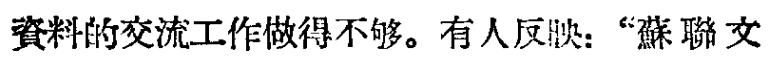

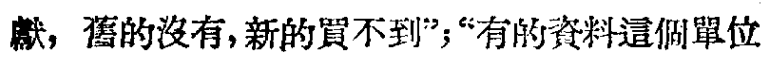
有, 茭的單位不知道”。這在一定程度上影響了我 椚的學替。

第二，缺乏學術討論、學術孚諭和學術上的 批評與自我批評。

声方面的工作, 有的研究所會做過一些。但 從全院來說, 還是没有適當的安排, 效果不大。 造次會議, 雖然有許多代表在報告中都進行了悬 術上的自我批評, 但由於這做會議不是專門性的 重洞討論會, 因此在學術上不能展開深入的討 䜽。大家都知道, 斯大柇的名言“沒有不同意見 的爭諭, 没有自由的批評, 任何科學都是不可能

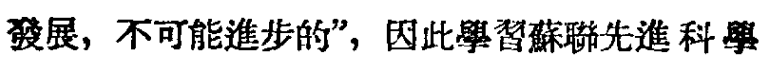
也必須注意開展學術上的批評。由於我椚在學術 問題上自由争論和批評與自我批評的風氣還沟有 很好地建立起來, 在一定程度上就妨碍了我們很
好地深入地向蘇聯學想。

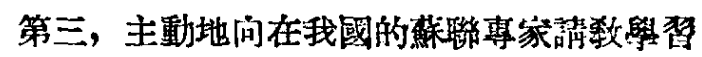

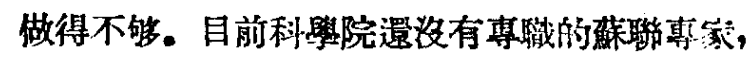
但是, 在衰業部門和高等學校, 蘇聯專家却是很 多的。他們都熱愛中國, 頋意無保留地煘中國人 民服務, 對於科學研究工作, 也都十分重視和閣 心, 能够給我們許多有力的瑶助與指導。但是玨 們除倜别研究所外, 主動地地蘇聯專家請数退做 得不够的，因而往往失去颜多良好的㙨偷。

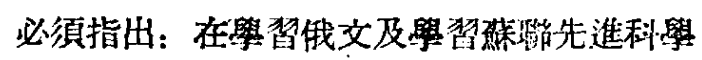
方面，我們取得的成績是主要的、基本啲。至於 在工作中的缺點, 我們正在逐步克服中, 是一定 可以克服的。同時, 也應當指出: 上述成綪的獲 得是全體利學工作人員積極努力的結果, 至於育 生上述缺點的原因, 主要由院的領導舀責, 演是 我們今後應當切實加以改進的。

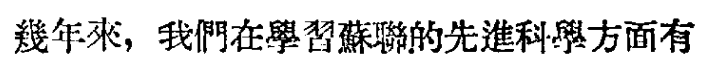
些什想經驗呢? 根據會議上所談的, 主要的有下 列六點。

（一）堅决走蘇聯科學㺕展的通路，學習蘇 聯先進科學要結合中國的實際, 要聯系我們的工 作。蘇聯科學是世界上最先進的、最優越的, 要

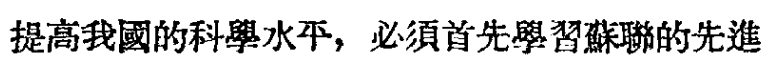

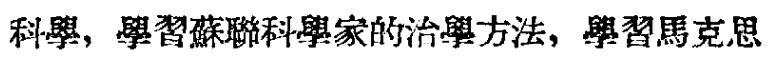

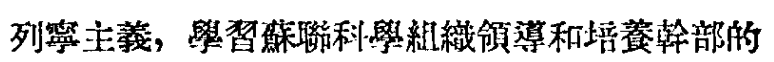
經驗。一句話, 就是堅决走蘇聯利燢發展的道路, 來發展我國的科學事業。但是學㥜独聯先進科學, 必須結合中國的打望際，繰合我們傕前的工作。道

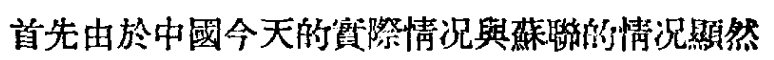

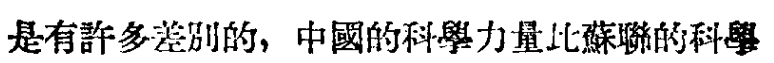
力量顯然莎弱得多, 要解决的問題繁然也是不畵 相同的。因此, 我們在學窗蘇照科學時, 一定要 反對那種不顧時間、地點、條件的荎别, 機械搬 運蘇聯科學的結論的敨佟主義的方法。特别是某 些帶地域性的科學部鬥，更須特别注意逻一點。 例如氣像方面的天氣分析工作，蘇聯的許多 件（緯度、地形、研究天氣所用工具等）與我国 不同，機械搬運，必定要犯錯譟，因此也然法解 决中國的中期天氣預報問題。地球物理研究所的 同志反對了選種敉條主義的學梠方法, 結合中國 䬭際情况, 創造性地運用蘇聯的先進理諭, 就得 到了良好的結果。其他如地質學、技術科學、社 
科菆都有同樣情形。蘇聨某些土壤學者，由於 不問地點條件的區別，直目推廣草田輪作制，造

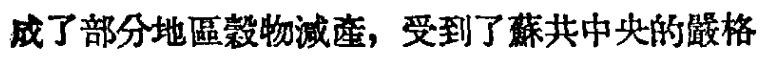
批尌，塄是值得我們很好地體會的。在反對敉條 主義的同時，我們也要反對那些狹险的實用主義 数點。他們學柏蘇聯，只想找現成的答案、現成 的配方或現成的結論，忽䤄系統理論的鑽研。但 是落聯科學的許多現成的答案與配方往往是不能 立即用於中國質際的, 假如因此認学不直接, 用 不上，就不學晳了，那是十分錯灌的。科學工作 是創造性的工作，繁唯聯先進科學也必須是創 造性的學習。這就是說，我們應着重地學替䰻聨 科罢的親點, 方法, 將它運用到我國實際中去, 以解决我們的頃際問題。上述中期天氣預報的研 究工作，由於他們同時反對了狹湓䆩用主義的傾

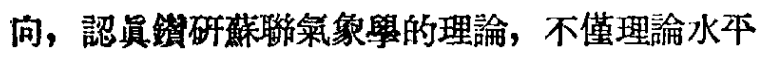
提高了, 也創造性地初步解决了中國的中期天氣 領報的實際問題。

（二）學劦蘇聯先進科學要有科學的態度 和窝事求是的精神。我們學習蘇聯先進科學，不 㮖要學習蘇聯科學的成就，更重要的是學習蘇聯

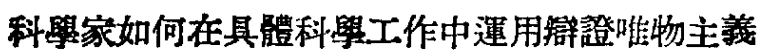
的世界觀與方法論的經驗，祭習他們在各門科學 領域內與唯心主義、形而上學淮行鬥爭的經驗, 習他們使科學服務於新會主義和共產主義建設 的經驗。我們礁當正確地理解他們的科學的體系 與㷋展的歴史, 批評與自我批訴的精㼛, 科學與 實践相結合、與人民相結合的發展通路。只有道

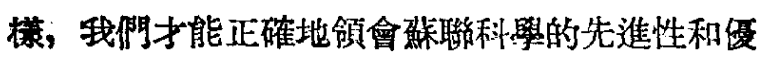
越性。在學習的過程中, 往往會發現蕉聯利學家 不僅批制資本主義國家科學中的錯誤的與反動的 嚾點，同時也批制蘇聨某些科學家過時的或鉷言誤 的論點。有的人竟由此認絾蘇聯科學也不一定都 是正確的、先進的, 就可以不必學㚙了。這種看

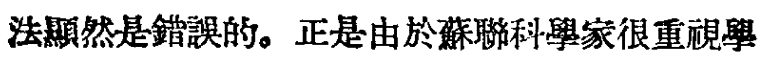
徆上的各種不同意見的討論和自由爭論, 不斷地 開展批訴與自我批評，批判和扡寨那些錯言的陳 的觀點和結論, 發拐那些正確的觀點和結論, 才使磁聯科學不斷地前進。因此，我們必須反對 不從蘇聯科是在先進理論思想指導下弡展起來 的科學，不從整個的蘇聯科學的先進理論體系來 看待蘇聯科雪，而只從枝筯的、個别的論點來看
待蘇聯科學的錯言吴觀點。同時我們也反對直目地、 不加分析地對待任何一篇蘇聯文獻的作法, 因篇 这同樣會阻塞我們前進的道路，妨碍我們從筑聯

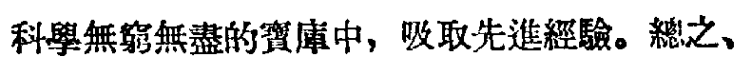

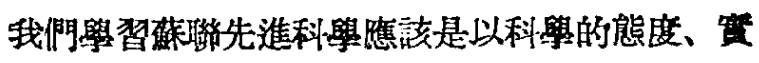
事求是的精神、全面的與發展的觀點來學習, 反 對盲目與輕率。物理研究所介紹例縃驗, 是佰得 注意的。他們的經驗告訴我椚，凡是過去在科學 工作上較有基礎的人, 學習蘇㗜科學著作, 必須 十分仔細和認真, 因篇有些䔉聯文缺中許多內容 是與資本主義國家科學文路大同小異的。“大同”

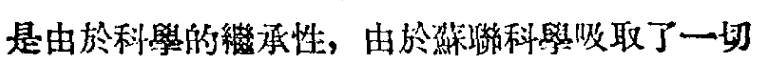

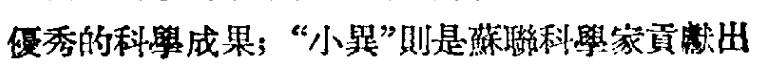
的新的結論或成果, 或者是對資本主義國家科學 的錯誤所作的批制。在這些方面我們如果不作細

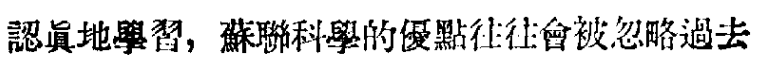
的。

（三）學習蘇聯先進科學要有领浔地、有計

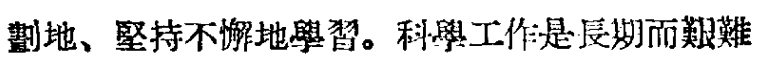

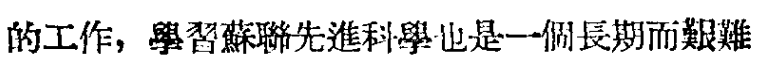

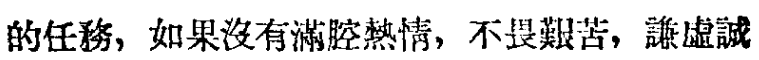

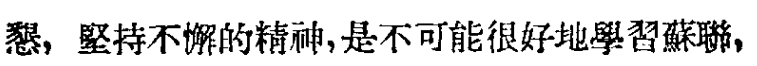
也不可能㮃登科學的高蔠的。到會的同志一致涊 篇堅持長期的學習，肯於付出大量的營動, 是成功

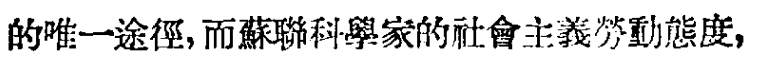

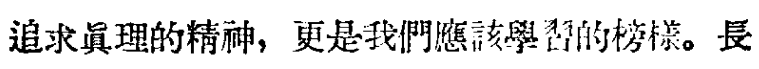
期的學習, 必須有領導、有計劃。这次會議上也 說明了那一單位領導得好、部劃得好, 學忽的成

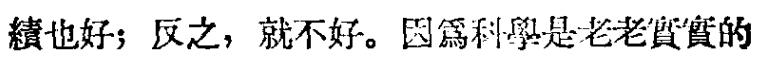

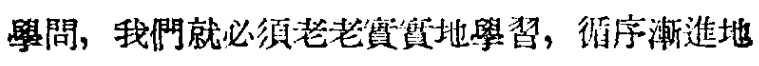
學習。一璟十寒的自由主義態度和急於求成的急 躁情緒都是不可能使我們學習好的。那種强調困 難、强調沟有時間、不樍極創造條件的消極等待 思想, 或不顧客觀條件, 無計劃、無系統地㳶抓 一把的作法, 都是有害的, 也都應該加以反對。

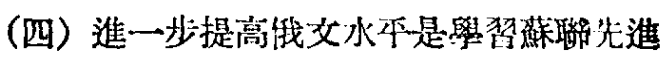
科學的重要佟件。科學院的䃑觉人員學难俄文是 有成綪的，大家的經驗是學習俄文最好與本身 業務相結合, 業務的需要就成䉆推動㧴文學翼的

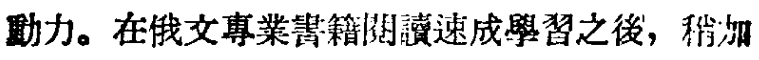
固, 挑選與本門業務有關且與自己水平相爱不 多 (最好稍高一點) 的俄交書進行閱讀翻摆, 
望固俄交是有势助的。基礎很美時, 過早地進行 翻澤工作也是不岁的。學替俄文必須長期堅持, 不要間斷。

在俄文學習方面，我門還只是開始，裳不能滿

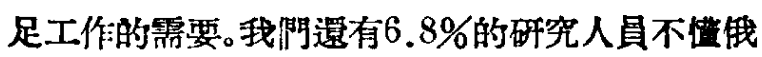
文, $19.7 \%$ 的研究人員踓學過俄文，但還不能運

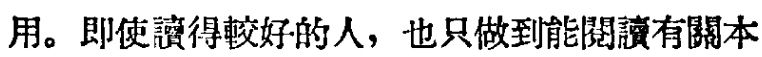
問業移的俄文交噳，一般都不能講話，不能寫作，

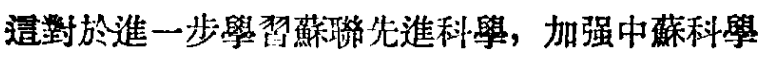
交流，都是不够的。今後，蘇聯科學家來中國恝 助我們工作的機會一定會更多的, 而我們十分缺

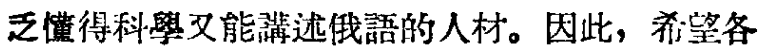
研究所在俄文學枋方面重點培養幾個研究工作人 員, 使他們能够滥話也能寫作, 通過他們來提高 我們學㕷蘇聯科學的質量與效果。至於高級研究 人員的俄文學柏, 首先隹保登他們的時間, 這是 帶動全體研究人員學習的關鍵。

（五）主動地问在我國的蔇聯專家請敎，貫 徹蘇聯專家建議, 是提高我們研究工作質量的最 直接的辡法。目前我國有不少蘇聯專家在文化、 經涑部門工作，他們都非常關心科學研究工作， 是我們最好的老師，我們要主動地向他們請敉， 並認真其徹專家的建議。在時間與條件允許的情 况下, 棓他們到研究所指導工作或派幹部到專家 工作單位去學習。這樣做，對於提高我椚的科學
水平與思想水平, 改進我門的工作方法與工作㦔 度, 都會有直接繁助。

（六）領導重視，保登時間，開展學術討論， 交流經驗，進一步深入地聚習蘇聯先進科學。一 般地說，各研究所的工作都是很忙的，今年我們

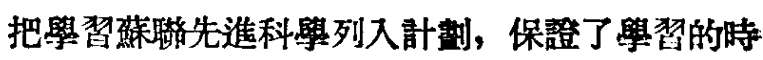
間, 加上有的研究所領導幹部以身作則, 對全䯏 人員學替蘇聯起很大推動作用。篇了使學㚙深入， 必須展開學術討論。術討論可探取多種多棦的

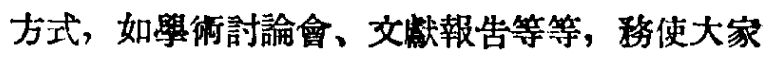
能有充分的交換不同意見的機會。在學術討論中， 任何武斷自大的態度都是有害的。我們要提倡在

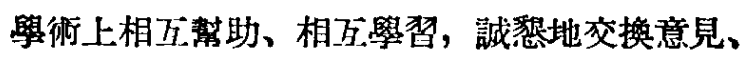
交流經驗的作風。這次會議可以說是經驗交流的: 開端, 以後我們還要更多地舉行不同內容、不同 範圍和不同形式的學衡討論會，使學術討論能够 廣泛地開展起來, 使學替蘇聯能够日益深入, 科 學水平能逐渐提高。

我們學習蘇聯先淮科學僈只是開始, 在通次 會議上,我們㗹該吸取經驗㕁訓並加以傳播推廣, 使在巳有的成結的基礎上, 改進學替的組織领运, 改進學習方法, 提高俄文水平, 開展學術討論, 加强對蘇聯先進科學及䛨證唯物主義的學習，以 發展我國的科學研究事業。 